\title{
The Effects of Zinc-Oxide Nanoparticles on Growth Parameters of Corn (SC704)
}

10.17975/sfj-2015-011

AUTHORS: Melika Taheri ${ }^{1,2}$, Hania Ataiei Qarache ${ }^{1,3}$, Alimohammad Ataei Qarache ${ }^{1}$, and Mahdieh Yoosefi ${ }^{{ }^{1}}$

SCHOOLS: 1. Research Center of Ostad-Taaher, Department of Education and Training, Shahreza, Iran.

2. Saleh School, Shahreza, Iran.

3. Shahed Shahid Bahrami High School, Shahreza, Iran.

\section{Abstract}

Nanoparticles are widely used in various fields like medicine and agriculture. Plant growth is hindered in mineral poor soils. Supplementing mineral poor soils can improve plant growth. One role of nanoparticles in agriculture is stimulating crop growth. In this study, the three different physical forms of $\mathrm{ZnO}$ particles in irrigation water were used to supplement mineral poor soil. Their effect on the growth of single cross 704 (SC704) corn was investigated. We studied the effects of ZnO nanocolloid, ZnO nanoparticles, and micrometric $\mathrm{ZnO}$ particles. The concentration of nanoparticles in irrigation water was $2 \mathrm{ppm}$. The results show that the addition of all three Zn0 particle types in irrigation water improved shoot dry matter and leaf area index. The best results came from the $\mathrm{ZnO}$ nanoparticle treatment which on average, increased the shoot dry matter and leaf area indexes by $63.8 \%$ and $69.7 \%$ respectively. Based on these results, we can conclude that zinc nanoparticles can improve corn growth and yield in mineral poor soils.

\section{Keywords}

Zinc Oxide, Nanoparticles, Agriculture.

\section{Introduction}

Nanotechnology use is expanding rapidly in every science field including various agricultural divisions. The properties of nanoparticles between 1 and 100 nanometers differ compared with their primary forms (1). In recent years, the addition of elements in nanoparticle form to plant environments has been considered and positive effects have been reported. In a study by Pandeyet et al., the addition of zinc oxide nanoparticles resulted in more pea growth than the addition of microparticles (2). Micro element deficiency in cereal farms is common and millions of hectares of the world's arable land are facing a shortage of one or more micro elements (3).

The United Nations' Food and Agriculture Organization collected data from 30 countries and report that more than $30 \%$ of soils have zinc deficiency (4). In Iran, studies have shown severe zinc deficiency in $40 \%$ of irrigated wheat fields (5). Zinc is a necessary micro element for people and livestock as well as plants. In many plant enzymatic systems, zinc plays active catalytic or constructional role.

Zinc deficiency can lead to disorders in factors regulating growth in plants (6). It decreases grain yield, plant protein percentage,and the nutritional value of products. Low zinc concentrations in grains can lead to zinc deficiency in humans. In a study in Tehran on 881 students, $50 \%$ showed signs of zinc deficiency (4). Corn is one of the most sensitive plants to zinc deficiency. In soils with severe zinc deficiency, a chlorotic stripe appears on one or both sides of the central veins in the first two weeks of growth. This yellow stripe is observed mostly on the lower part of the leaves. Zinc deficiency decreases the amount of growth regulator, resulting in shorter internodes on the stem. Another sign of zinc deficiency is curly leaf edges (5).

Few studies have investigated the effects of nanoparticles on corn growth. Among the metal oxides, zinc oxide nanoparticles have attracted attention due to their extensive properties. Zinc oxide is recognized as a safe substance by the United States Food and Drug Administration. Zinc salts are used in the treatment of zinc deficiency in humans. The antimicrobial effects of metal nanoparticles, including zinc oxide nanoparticles, have been noted in recent years. The considerable antimicrobial effect and low cost of zinc oxide nanoparticles have led to them being considered for application in the food industry to reduce bacterial growth (2). This study was conducted to investigate the effects of zinc-oxide nanoparticles on the growth and dry weight of corn-SC704 in mineral poor soils.

\section{Materials and Methods}

Corn (SC 704) seeds were cultivated in four liter pots filled with mineral poor soil (cultivation depth $3 \mathrm{~cm}$ ). Five seeds were cultivated in each pot. After a while, extra plants were eliminated and three plants were kept. Pots were divided into four groups with eight pots in each group. In order to maintain the soil moisture at field capacity, irrigation was performed daily. Zinc oxide nanoparticles were purchased from Green Nano-chemistry Co. (Iran). The Nanoparticle (Group 3), properties are presented in table 1. 
Table 1: Properties of nanoparticles

\begin{tabular}{|c|c|c|c|c|c|}
\hline $\begin{array}{l}\text { Nano } \\
\text { purtidt } \\
\text { type }\end{array}$ & $\begin{array}{l}s i x \\
\Leftrightarrow\end{array}$ & $\begin{array}{l}\text { Speciix } \\
\text { area (nof) }\end{array}$ & $\begin{array}{c}\text { Puiby } \\
\text { percempernge }\end{array}$ & Strutare & 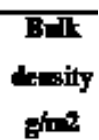 \\
\hline $2=0$ & 20 & 90 & $59+$ & क्रान & 0.65 \\
\hline
\end{tabular}

The leaf area index was measured using an AccuPar LP-80 apparatus. A digital pH meter Metrohm (827 pH Lab) was used to measure the $\mathrm{pH}$ of the irrigation water. Zinc nanocolloid was prepared using a wire electrical explosion machine. Zinc oxide nanoparticles were compared with zinc oxide. Zinc wires with a diameter of 200 microns were prepared and nanocolloid solution was made by wire electrical explosion (6). The colloid form was maintained by adding surfactant to the solution. Previous studies showed concentrations of $2 \mathrm{ppm}$ zinc oxide led to the best corn growth (7).Studies were carried out in four groups and with 8 pots in each group. The treatment groups were: control, zinc oxide nanocolloid, zinc oxide nanoparticle, and micrometric zinc oxide.

Group 1. Normal irrigation was performed.

Group 2. Irrigation with zinc nanocolloid was applied in three stages: one, two, and three weeks after corn emergence.

Group 3. Irrigation with zinc nanoparticles 2 ppm was applied in three stages: one, two, and three weeks after corn emergence ( $\mathrm{pH}$ was decreased from 7.4 to 7 to increase the solubility of zinc oxide).

Group 4. Irrigation with micrometric zinc oxide (2 ppm) was applied in three stages: one, two, and three weeks after corn emergence ( $\mathrm{pH}$ was decreased from 7.4 to 7 to increase the solubility of zinc oxide).
The best $\mathrm{pH}$ for irrigation water is neutral. The water in Shareza was 7.4 and so the $\mathrm{pH}$ level of all irrigation waters reduced to 7 . The condition and color of veins and leaf and aerial part growth were studied and compared to the control. Two weeks after the last treatment, plants were harvested and measurements were taken. A leaf area meter was used to measure the leaf area. Leaves were dried in an oven at $70^{\circ} \mathrm{C}$ for 48 hours. The resulting dry matter was weighed using an electric balance.

\section{Results and Discussion}

According to the results, each treatment with zinc oxide increased leaf area (figure 2 and 3). The vegetative growth period in determinate growth plants like corn is one of the most important phonological stages due to its impact on the yield (8). Leaves play an important role in photosynthesis. The rate of appearance and development of leaves are affected by various factors. Determining the precise time of leaf primordium formation or the time that the terminal meristem is formed is difficult. Therefore, when the length of the primordium reaches $10 \mathrm{~mm}$, that is considered to be the appearance of the first leaf (9).

Various studies have shown that element deficiency caused a delay in plant maturity due to a delay in leaf appearance and an increase in the vegetative growth period. Some research indicates that zinc deficiency and reduction in photosynthetic active radiation can affect the rate of appearance and growth of leaves (10). Corn and other tropical grains produce a complete leaf every four to six days. Low temperatures may cause delay in tassel production and reduce available nutrients due to delayed leaf appearance (10). Zinc is an important element to plants and is a significant limiting factor of plant growth. Iran is arid and semi-arid and its soil has limited organic matter.

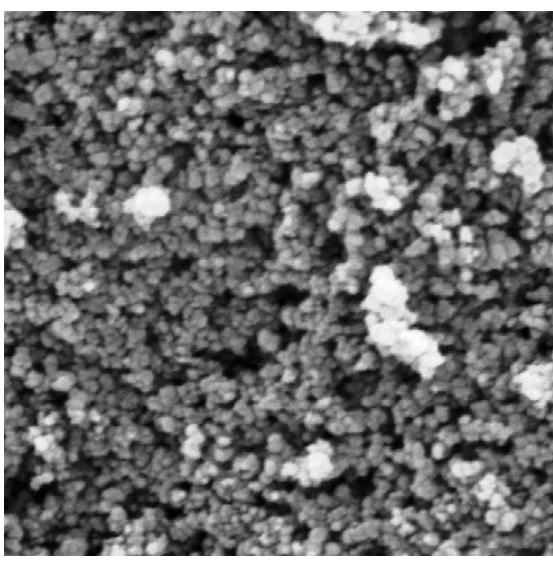

Figure 1-1

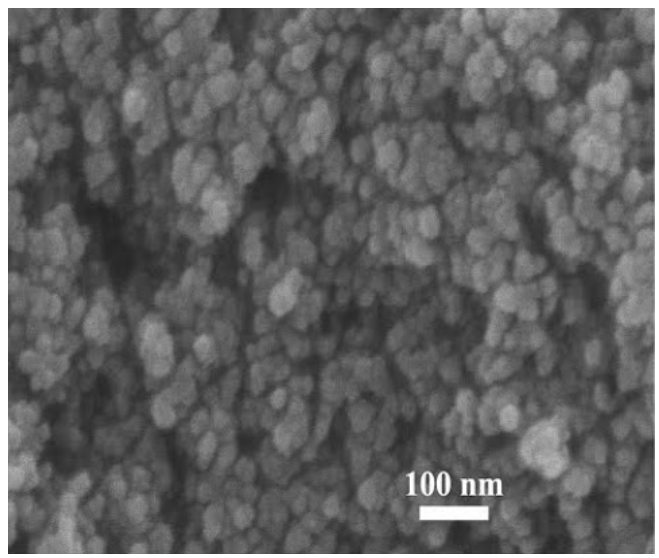

Figure 1-2

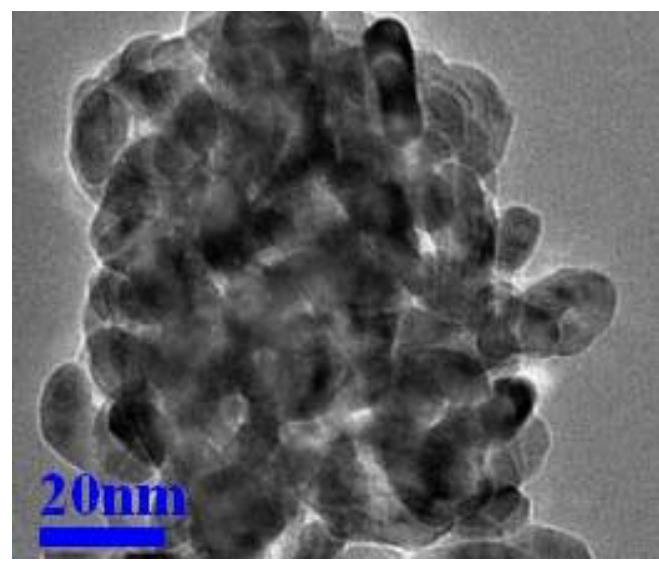

Figure 1-3

Figure 1: Electron microscope images of nanoparticles. Scanning electron microscope (SEM) of nanoparticles (Group 3) are shown. 
Table 2: Leaves morphological properties. Results of leaves morphological properties are shown.

\begin{tabular}{|c|c|}
\hline 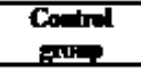 & 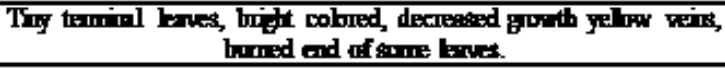 \\
\hline 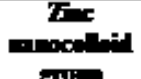 & 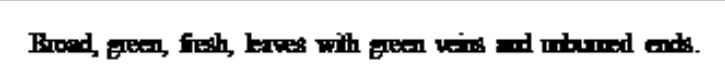 \\
\hline 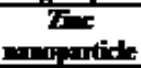 & 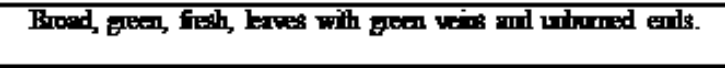 \\
\hline 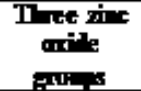 & 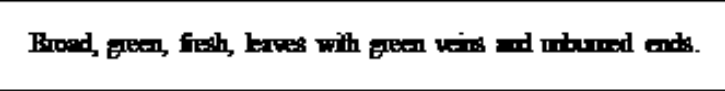 \\
\hline
\end{tabular}

Studies have reported differing reactions amongst corn hybrids to nitrogen and zinc fertilizer (11), The lack of zinc and nitrogen or reduction of supplementation delayed leaf appearance. Supplementation expedited leaf appearance. By increasing fertilizer levels, grain yield per area unit was increased in all corn cultivars (12). Using $240 \mathrm{~kg} / \mathrm{ha}$ of nitrogen (in vitro) accelerated leaf appearance of C-404 cultivar, reduced phyllochron and increased grain yield. In this current study, irrigation with zinc oxide nanoparticles improved growth, leaf area, and leaf dry weight. Both nanoparticles

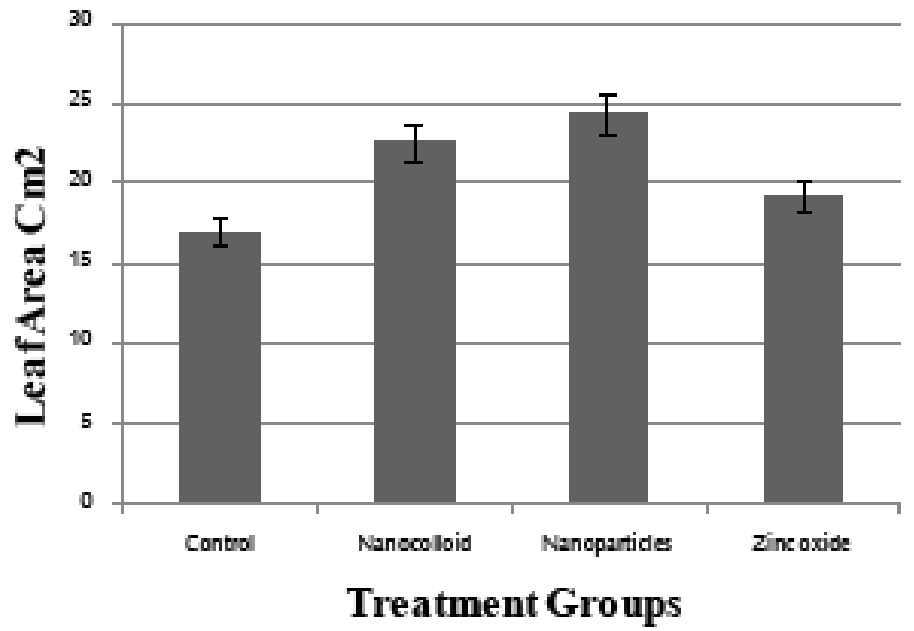

Figure 2: Comparison of mean leaf area in treatment groups. Figure 2 shows the results of leaf area means in all treatment groups. met corn's need for zinc. Additionally, both nanoparticle groups performed better than the zinc oxide group due to their nano properties. This was attributed to higher specific surface area of $\mathrm{ZnO}$ nanoparticles compared to micro particles. The higher surface area led to better contact between $\mathrm{ZnO}$ and soil elements. In other words ZnO nanoparticles absorbed more efficiently and were the probable cause of increased plant growth.

\section{Conclusion}

This study compared the effects of zinc oxide nanocolloid, zinc oxide, and zinc oxide nanoparticles on the growth of corn. Irrigation with all zinc oxide particles improved growth, leaf area, and leaf dry weight.

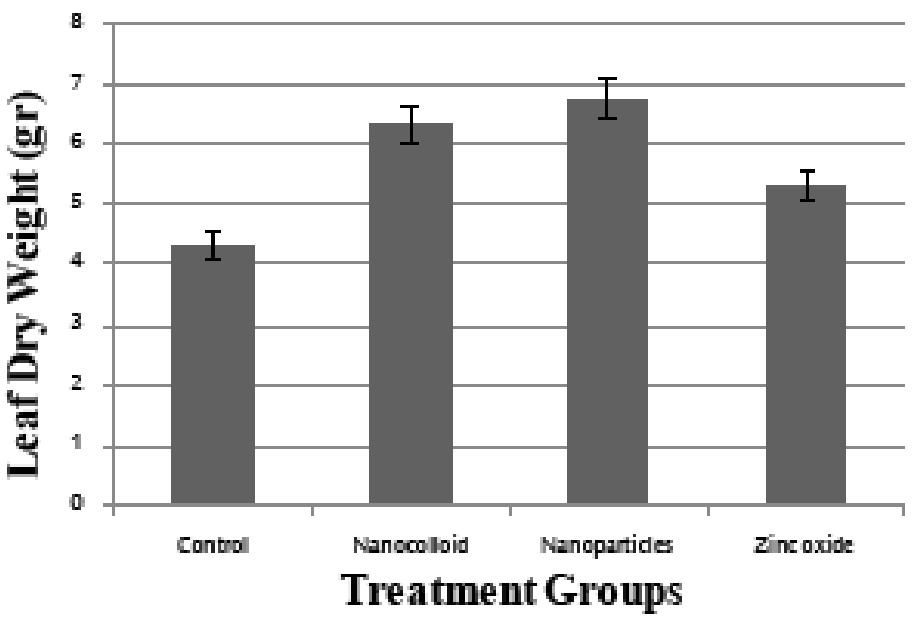

Figure 3: Comparison of mean leaf dry weight in treatment groups. Figure 3 shows the results of leaf dry weight means in all treatment groups.

\section{Acknowledgements}

This paper is based on work supported by the Nanoclub and the Ostad-Taher research center. We are immensely grateful to Nanoclub for $70 \%$ financial support to equip our lab. We would like to show our gratitude to Mr. Jali, the head of Ostad-Taher Research Center for his technical assistance. We also would like to thank Dr. Pashaei for providing comments that greatly improved the manuscript. 


\section{References}

1. Lloyd JR, Macaskie LE. Bioremediation of Radionuclide-Containing Wastewaters. Environmental Microbe-metal Interactions: American Society of Microbiology; 2000.

2. Pandey AC, S. Sanjay S, S. Yadav R. Application of ZnO Nanoparticlesin Influencing the Growth Rate of Cicer Arietinum. Journal of Experimental Nanoscience. 2010;5(6):488-97.

3. Lovley DR, Phillips EJP, Gorby YA, Landa ER. Microbial Reduction of Uranium. Nature. 1991;350(6317):413-6.

4. Moore JW. Inorganic Contaminants of Surface Water. United State: Springer-Verlag; 1991.

5. Chan WCW, Maxwell DJ, Gao X, Bailey RE, Han M, Nie S. Luminescent Quantum Dots for Multiplexed Biological Detection and Imaging. Current Opinion in Biotechnology. 2002;13(1):40-6.

6. Bac Luomg , Jisoon Kim Synthesis \& characterization of nano_ sized zn powder by electrical explosion . world scientific 28 octobr 2015 3903-3909

7. Cheeseman, J.M. and L.K. Wickens. 1986. Control of Na+ and K+ transport in Speragulariamorina. III.Relationship between ion uptake and growth at moderate salinity. Physiology. Plant. 67: 15-22.

8. Laegreid M, Bockman OC, Kaarstad O. Agriculture, Fertilizers and the Environment. United Kingdom: CABI Publishing; 1999.

9. Mahmood MT, Maqsood M, Awan TH, Sarwar R. Effect of Different Levels of Nitrogen and Intra-Row Plant Spacing on Yield and Yield Components of Maize. Pakistan Journal of Agricultural Sciences. 2001;38(1-2):48-9.

10. Berglund DR, Endres GJ, McWilliams DA. Corn Growth and Management Quick Guide. United States: North Dakota State University; 1999.

11. Cicek, N., and Cakirlar, H. 2002. The effect of salinity on some physiological parameters in two maize cultivar.Journal of plant physiology. 28: 66-74.

12. McMaster GS. Phenology, Development, and Growth of the Wheat (Triticum Aestivum L.) Shoot Apex: A Review. Advances in agronomy. 1997;59:63-118.

\section{REVIEW}

\section{by Dr. Fatemeh Pashaei Soorbaghi,}

\section{Student Nanoclub, Iranaian Nano Initiative}

In this work the authors were interested in the incorporation of nanotechnology. A considerable approach was suggested for the investigation of nanoparticles for the growth of corn in poor soils. It should be stated that, the authors were presented with the second award in the 6th Nanotechnology festival which was held from 5th to 8th October 2015 in Tehran. The main aspect of this work is the comparison between the effects of different types of zinc oxide nanoparticles and micrometric particles on corn growth. The paper is well written and has satisfied the requirements of a research paper. Data analysis and graphs are beneficially used for the interpretation of results. The results confirm the merit advantages of nanoparticle in comparison with microparticles for poor soil enrichment. In addition, in this research, the authors have generated the production of nanoparticles. For this purpose, they conducted an experiment to produce zinc oxide nano particles using the electrical wire explosion method. Although the authors have explained the line of reasoning they follow, some further adjustments and modifications are required. First and foremost, it is necessary to discuss in details the effect of zinc oxide concentration on plant growth. Additionally, the $\mathrm{pH}$ level of all irrigation waters should be stated due to importance of the effect of water $\mathrm{pH}$ on plants growth. Although the preparation of zinc nanoparticles in water guarantees the formation of zinc oxide nanoparticles to some extent, in order to reach more reliable and comprehensive results, chemical and morphological characterization of as-prepared nanoparticles is recommended. 